Article

\title{
Stress Corrosion and Corrosion Fatigue of Biodegradable Mg-Zn-Nd-Y-Zr Alloy in In-Vitro Conditions
}

\author{
Lilach Elkaiam*, Orly Hakimi and Eli Aghion \\ Department of Materials Engineering, Ben-Gurion University of the Negev, Beer-Sheva 8410501, Israel; \\ orlyhakimi5@gmail.com (O.H.); egyon@bgu.ac.il (E.A.) \\ * Correspondence: lilachelkaiam@gmail.com
}

Received: 14 May 2020; Accepted: 11 June 2020; Published: 14 June 2020

\begin{abstract}
Mg}$ alloys are attractive as a structural material for biodegradable implants due to their mechanical properties, biocompatibility and degradation capability in physiological environments. However, their accelerated corrosion degradation, coupled with their inherent sensitivity to stress corrosion, can cause premature failure and consequently loss of mechanical integrity. This study aims to evaluate the potential of a $\mathrm{Mg}-5 \% \mathrm{Zn}$ alloy with up to $3 \% \mathrm{Nd}$ as an implant material in terms of stress corrosion performance in in vitro conditions. Stress corrosion behavior was evaluated under static loading conditions using slow strain rate testing (SSRT) analysis and under low cycle corrosion fatigue (LCCF). Both the SSRT analysis and LCCF testing were carried out in a simulated physiological environment in the form of a phosphate-buffered saline (PBS) solution. The obtained results indicate that the addition of up to $3 \% \mathrm{Nd}$ to $\mathrm{Mg}-5 \% \mathrm{Zn}$ alloy did not have any substantial influence on the stress corrosion susceptibility, beyond the inherent different mechanical properties of the tested alloys. This was attributed to the limited effect of the $\mathrm{Nd}$ on the passivation layer and due to the fact that the secondary phases produced by the $\mathrm{Nd}$ additions- $-\mathrm{W}$-phase $\left(\mathrm{Mg}_{3}(\mathrm{Nd}, \mathrm{Y})_{2} \mathrm{Zn}_{3}\right)$ and T-phase $\left(\mathrm{Mg}_{4}(\mathrm{Nd}, \mathrm{Y}) \mathrm{Zn}_{2}\right)$ - did not create any substantial micro-galvanic effect.
\end{abstract}

Keywords: magnesium; biodegradable; stress corrosion cracking; corrosion fatigue

\section{Introduction}

Mg alloys have attracted significant attention as potential structural materials for biodegradable implants due to their excellent biocompatibility, degradation capabilities in physiological environments, and appropriate mechanical properties [1-4]. The relatively low elastic modulus and low density of $\mathrm{Mg}$ alloys are similar to human bone, consisting of $41-45 \mathrm{GPa}$ and $1.74-2.01 \mathrm{~g} / \mathrm{cm}^{3}$ compared to 3-20 GPa and 1.8-2.1 g/ $/ \mathrm{cm}^{3}$, respectively. Non-compatible mechanical properties may have a detrimental effect on the healing process of bones and can induce the danger of stress shielding following orthopedic operations. The main limitation of $\mathrm{Mg}$ alloys relates to their accelerated corrosion in physiological environments that can lead to premature failure and subsequent loss of mechanical integrity. Furthermore, the accelerated corrosion of $\mathrm{Mg}$ alloys can produce an accumulation of hydrogen gas through the following chemical reaction: $\mathrm{Mg}(\mathrm{s})+2 \mathrm{H}_{2} \mathrm{O}(\mathrm{l}) \rightarrow \mathrm{Mg}(\mathrm{OH})_{2}(\mathrm{~s})+\mathrm{H}_{2}(\mathrm{~g})$. Hydrogen gas formation can create gas bubbles in the vicinity of the implants, which can result in tissue separation and, in extreme cases, in gas embolism [5]. Guangling Song [6] reported that the human body can tolerate hydrogen gas emissions of up to $0.01 \mathrm{~mL} / \mathrm{cm}^{2} /$ day. This means that the hydrogen evaluation rate during the degradation process of $\mathrm{Mg}$ based implants should be lower than this value, in practice.

An additional and substantial concern related to Mg alloy implants is their inherent sensitivity to stress corrosion failure. This type of failure occurs under the combined effect of stress loading and a 
corrosive environment. The stress loading can be either static or cyclic, depending on the operational conditions of the implants. Despite several research studies having already been carried out in order to characterize the stress corrosion performance of $\mathrm{Mg}$ based implants [7-12], this phenomenon is still not well understood. Some of these studies indicated that the stress corrosion mechanisms were associated with anodic dissolution and hydrogen embrittlement. In the case of cyclic loading, a pitting corrosion attack may be one of the main detrimental effects that plays a dominating role in fatigue crack nucleation.

Interest in $\mathrm{Mg}-\mathrm{Zn}$ based alloys mainly stems from the excellent biocompatibility of $\mathrm{Zn}$ and its beneficial effect on the mechanical properties of $\mathrm{Mg}$ [13-15]. Furthermore, $\mathrm{Zn}$ is also considered to be a vital element for basic biological processes, due to its participation in nucleic acid metabolism, signal transduction and apoptosis regulation [16]. Several research studies were performed on $\mathrm{Mg}-\mathrm{Zn}$ based alloys with the addition of various alloying elements [17-19]. Rokhlin et al. [20] found that the addition of $\mathrm{Nd}$ and $\mathrm{Cd}$ to a $\mathrm{Mg}-\mathrm{Zn}-\mathrm{Zr}$ alloy increased the stress corrosion resistance. Ben Hamu et al. [21] reported that the stress corrosion performance of $\mathrm{Mg}-\mathrm{Zn}-\mathrm{Mn}$ alloys was improved upon the addition of Si. Wang et al. [22] reviewed the fatigue behavior of $\mathrm{Mg}$ alloys in an aqueous medium with a focus on the effect of the microstructure, anodic dissolution, hydrogen embrittlement, heat treatment and surface protection on the corrosion fatigue failure. They concluded that the mechano-chemical interaction mechanisms in the fatigue failure of $\mathrm{Mg}$ alloys were still superficial in terms of adequate alloying design and practical application in service conditions.

The present study aims to evaluate the effect of the addition of up to $3 \% \mathrm{Nd}$ on the stress corrosion performance of a $\mathrm{Mg}-5 \% \mathrm{Zn}$ alloy in terms of slow strain rate testing (SSRT) analysis and low cycle corrosion fatigue (LCCF). The selection of $\mathrm{Nd}$ as an alloying element was due to its anti-carcinogenic and non-cytotoxicity properties in in vivo conditions [23], as well as its anticipated beneficial effect on mechanical properties.

\section{Materials and Methods}

Based on the material system $\mathrm{Mg}-\mathrm{Zn}-\mathrm{Nd}-\mathrm{Y}-\mathrm{Zr}$, four different $\mathrm{Mg}$ alloys were prepared using high purity alloying elements (99.9\%). The pure $\mathrm{Mg}(99.8 \%)$ was melted in a steel crucible under a protective gas atmosphere of $\mathrm{CO}_{2}+\mathrm{HFC} 134$. The molten $\mathrm{Mg}$ was superheated to $775{ }^{\circ} \mathrm{C}$ and the alloying elements- Zn, Y, Zr and $\mathrm{Nd}$ (via a Mg-20\% Nd master alloy)—were added according to the designated chemical composition of the alloys, while the molten metal was under intensive stirring for $20 \mathrm{~min}$. This was followed by a settling stage of $30 \mathrm{~min}$ to allow heavy elements and other substances such as magnesium oxide to settle at the bottom of the crucible [24-26]. The obtained alloys were cast in a steel mold to obtain $16 \mathrm{~kg}$ ingots. The chemical composition (Table 1) of the four alloys obtained by this process was determined by mass spectrometry (Baird-Bedford, Bedford, MA, USA) as follows [27]:

Table 1. Chemical composition of the tested alloys (in wt\%) (data from [27]).

\begin{tabular}{cccccccccc}
\hline $\begin{array}{c}\text { Alloy } \\
\text { Compositions }\end{array}$ & Zn & Nd & Zr & Y & Fe & Si & Ni & Cu & Mg \\
\hline Mg-5\% Zn & 5.1 & 0.0 & 0.38 & 0.15 & 0.005 & 0.01 & 0.001 & 0.001 & Balanced \\
$\mathrm{Mg}-5 \% \mathrm{Zn}-1 \% \mathrm{Nd}$ & 5.0 & 1.2 & 0.36 & 0.14 & 0.008 & 0.01 & 0.001 & 0.001 & Balanced \\
$\mathrm{Mg}-5 \% \mathrm{Zn}-2 \% \mathrm{Nd}$ & 5.1 & 2.1 & 0.33 & 0.12 & 0.006 & 0.01 & 0.001 & 0.001 & Balanced \\
$\mathrm{Mg}-5 \% \mathrm{Zn}-3 \% \mathrm{Nd}$ & 5.2 & 3.2 & 0.35 & 0.12 & 0.006 & 0.01 & 0.001 & 0.001 & Balanced \\
\hline
\end{tabular}

In order to upgrade the mechanical properties of the cast alloys, they were homogenized at a temperature of $320^{\circ} \mathrm{C}$ under a protective gas atmosphere of Air/ $\mathrm{CO}_{2}+\mathrm{SF}_{6}$ for $8 \mathrm{~h}$. This was followed by rapid quenching in hot water at a temperature of $80^{\circ} \mathrm{C}$. The cylindrical bars of $60 \mathrm{~mm}$ length and $50 \mathrm{~mm}$ diameter were prepared by machining for the extrusion process. The extruding process was carried out at $400{ }^{\circ} \mathrm{C}$ using an extrusion ratio of $8: 1$ to obtain rectangular bars of $15 \times 15 \mathrm{~mm}^{2}$. 
The microstructure of the extruded alloys was examined using a scanning electron microscope (SEM, JEOL-5600, Peabody, MA, USA) [28].

The stress corrosion behavior under static load conditions was evaluated by slow strain rate testing (SSRT) using a Cromat C-76 set-up according to the ASTM G129-00 standard. The strain rates used by the SSRT analysis were $2.5 \times 10^{-5}-2.5 \times 10^{-7} \mathrm{~s}^{-1}$. The gauge length and diameter of the SSRT samples were $25.4 \mathrm{~mm}$ and $3.81 \mathrm{~mm}$, respectively. The stress corrosion properties under the cyclic loading conditions were examined by low cycle corrosion fatigue (LCCF) tests using a standard bending machine apparatus [29]. The dimensions of the fatigue specimen were: total length, $80 \mathrm{~mm}$; neck span, $16 \mathrm{~mm}$; radius of curvature at the neck, $12.5 \mathrm{~mm}$; and thickness, $3 \mathrm{~mm}$. The LCCF test parameters included a strain amplitude of $2 \%$ and a frequency of $0.4 \mathrm{~Hz}$.

Both the SSRT analysis and LCCF testing were examined in in vitro conditions using a simulated physiological environment in the form of a phosphate-buffered saline (PBS) solution. The chemical composition of the PBS solution includes a $0.01 \mathrm{M}$ phosphate buffer 0.0027 M Potassium Chloride $0.137 \mathrm{M}$ Sodium Chloride in $200 \mathrm{~mL}$ deionized water. For reference, the LCCF tests were also carried out in air to simulate non-corrosive conditions. Prior to the SSRT and LCCF tests, all the samples were ground with $\mathrm{SiC}$ paper up to 1200 grit and cleaned in an ultrasonic bath for $5 \mathrm{~min}$. Following the SSRT analysis and LCCF testing, the corrosion products were removed according to the ASTM G1-03 standard using $\mathrm{CrO}_{3}, \mathrm{Ba}\left(\mathrm{NO}_{3}\right)_{2}, \mathrm{AgNO}_{3}$ in deionized water and alcohol for final cleaning. In order to examine the nature of the failure, the fracture surface of failed specimens was analyzed using a stereoscope apparatus (LEICA 24D).

\section{Results}

The typical microstructures of the tested alloys, captured by the SEM imagers are shown in Figure 1. This reveals that the microstructure of the base alloy, Mg-5Zn, was mainly composed of a $\alpha$-Mg matrix with dissolved $\mathrm{Zn}$. This complies with the fact that the solid solubility of $\mathrm{Zn}$ in $\mathrm{Mg}$ is up to $6.2 \mathrm{wt} \%$ in the form of a eutectic system. According to a previous study by the authors [27], and a number of other studies [30-33], additions of up to $2 \mathrm{wt} \% \mathrm{Nd}$ created a secondary phase at the grain boundaries in the form of a W-phase- $-\mathrm{Mg}_{3}(\mathrm{Nd}, \mathrm{Y})_{2} \mathrm{Zn}_{3}$, while the addition of $3 \mathrm{wt} \% \mathrm{Nd}$ also created a T-phase- $\mathrm{Mg}_{4}(\mathrm{Nd}, \mathrm{Y}) \mathrm{Zn}_{2}$. The mechanical properties of the tested alloys, as found in our previous study [27], indicated that the average ultimate tensile strength (UTS) and elongation values of the base alloy (Mg-5Zn) were $310 \mathrm{MPa}$ and $18.5 \%$, respectively. The addition of 1 and $2 \mathrm{wt} \% \mathrm{Nd}$ resulted in increases of the UTS value to $340 \mathrm{MPa}$ and $360 \mathrm{MPa}$, respectively, while the addition of $3 \mathrm{wt} \% \mathrm{Nd}$ did not have any significant effect, as it yielded a UTS of $350 \mathrm{MPa}$. In terms of ductility, additions of 1,2 and $3 \mathrm{wt} \% \mathrm{Nd}$ to the base alloy reduced the average elongation to $12 \%, 16 \%$ and $14 \%$, respectively. Additionally, it was shown that the corrosion performance of the tested alloys, in terms of an immersion test, and potentiodynamic polarization and electrochemical impedance spectra analyses were similar. This clearly indicated that the $\mathrm{Nd}$ addition had a relatively insignificant effect on the corrosion resistance of the base alloy.

The results of the stress corrosion analysis obtained by the SSRT in a PBS solution in terms of stress-strain curves is shown in Figure 2, while a summary of the results of the UTS and elongation versus strain rate is shown in Figures 3 and 4, respectively. This reveals that the UTS and elongation of all the tested alloys were reduced as the strain rate was decreased, due to the detrimental effect of the corrosive environment. However, the inherent differences in the mechanical properties of the various alloys were relatively well-maintained for all the tested strain rates. This clearly indicates that the addition of up to $3 \% \mathrm{Nd}$ did not have any significant effect on the stress corrosion sensitivity of the base alloy Mg-5Zn. Furthermore, the values of elongation to failure for all tested alloys, presented in Figure 4, were lower than those obtained in air in our previous study [27]. This reduction in the elongation values suggests the presence of corrosion sensitivity in all tested alloys. The time to failure versus strain rate in terms of the SSRT analysis is presented in Figure 5. This reveals that the time to 
failure of all the tested alloys increased as the strain rate decreased. In addition, all the tested alloys exhibited similar durability at all the strain rates.
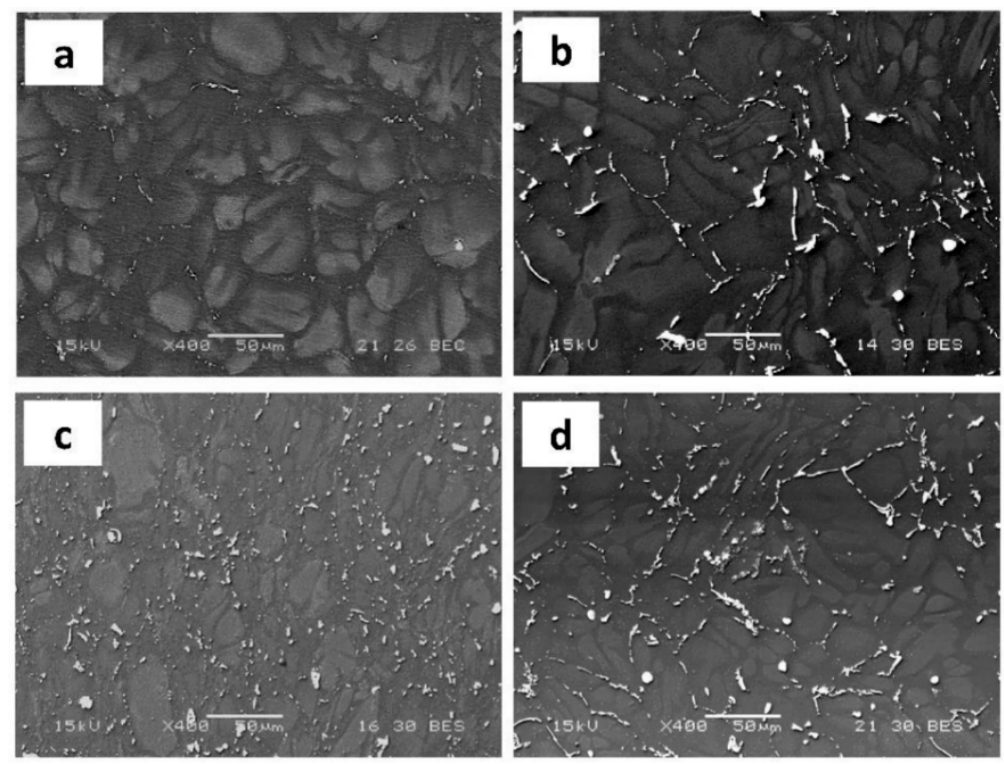

Figure 1. Typical microstructure of the tested alloys from SEM images: (a) Mg-5Zn; (b) Mg-5Zn- $1 \mathrm{Nd}$; (c) Mg-5Zn-2Nd and (d) Mg-5Zn-3Nd.

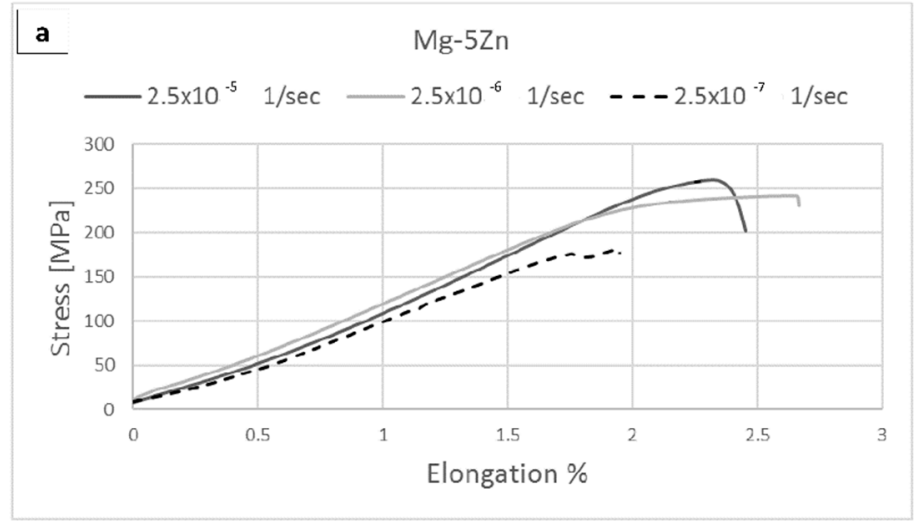

Figure 2. Cont. 

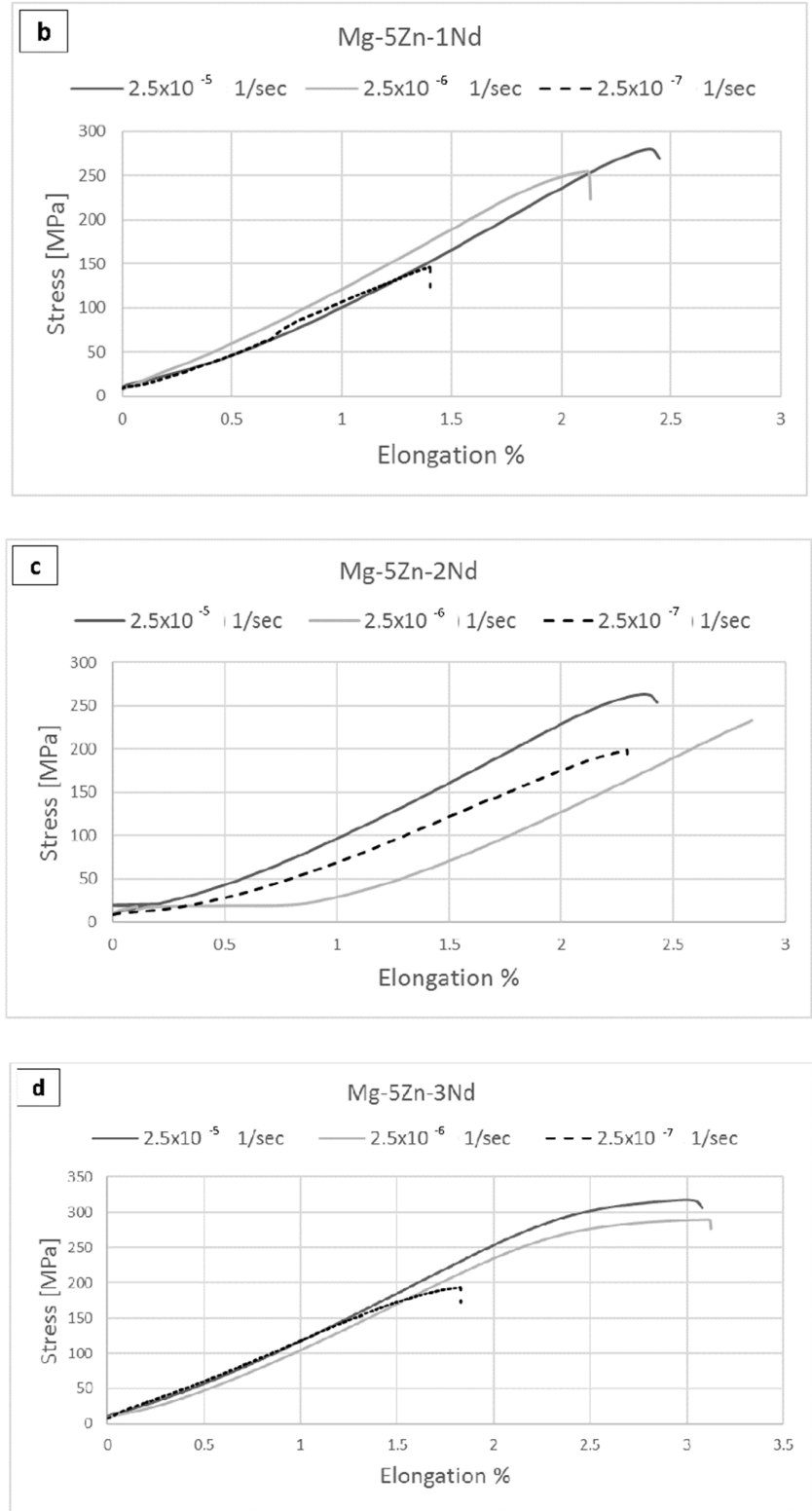

Figure 2. The stress-strain curves of (a) Mg-5Zn; (b) Mg-5Zn-1Nd; (c) Mg-5Zn-2Nd and (d) Mg-5Zn-3Nd at various strain rates in phosphate-buffered saline (PBS); slow strain rate testing (SSRT) obtained by the SSRT analysis.

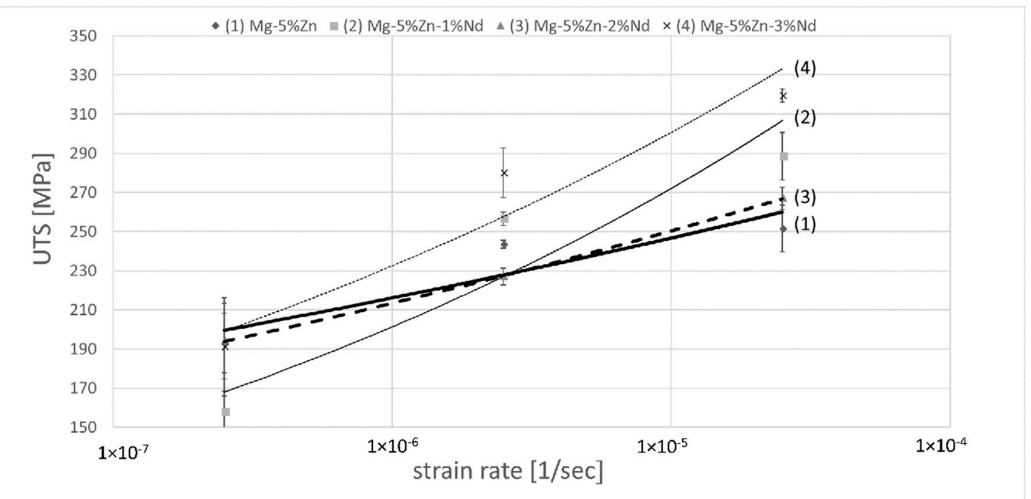

Figure 3. The ultimate tensile strength versus strain rate as obtained by the SSRT analysis for four different alloys. 


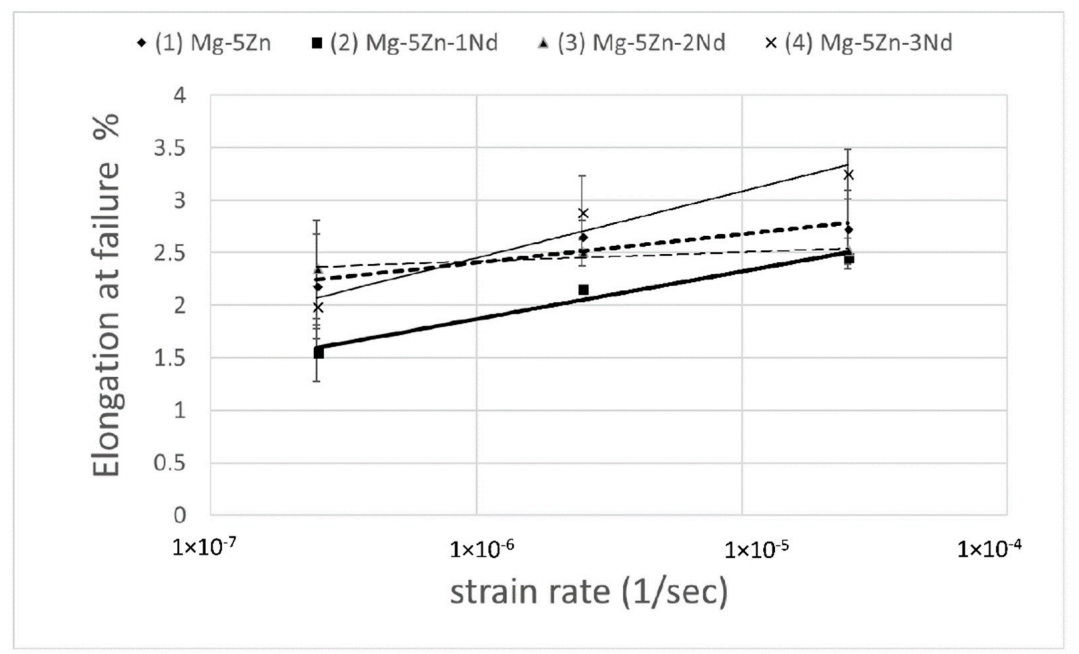

Figure 4. The elongation versus strain rate obtained by the SSRT analysis for four different alloys.

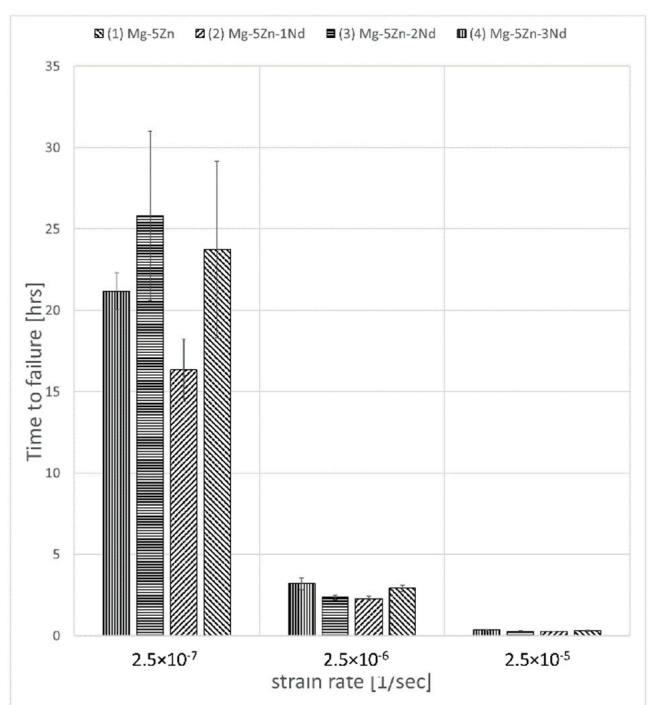

Figure 5. The time to failure versus strain rate obtained by the SSRT analysis for four different alloys.

The typical fracture analysis of a few of the tested alloys following the SSRT, at strain rates of $2.5 \times 10^{-5} \mathrm{~s}^{-1}$ and $2.5 \times 10^{-6} \mathrm{~s}^{-1}$ are shown in Figures 6 and 7, respectively, after the removal of corrosion products. At a high strain rate of $2.5 \times 10^{-5} \mathrm{~s}^{-1}$, all the tested alloys displayed similar fracture surfaces that contained two distinct regions: the pure mechanical overload zone (dark area) and stress corrosion cracking (SCC) zone (white area). The SCC zone was characterized by crack branching, which is usually generated under high stress conditions where the structural material is not capable of releasing the high energy in a single crack. Hence, it appears that under a high strain rate, there was not enough time to develop the SCC conditions, and all the tested alloys broke mainly due to overload. As the strain rate was decreased, the stress corrosion area became significantly larger with an almost non-detectible overload zone. This was clearly evident from the fracture surfaces obtained at the lowest strain rate of $2.5 \times 10^{-7} \mathrm{~s}^{-1}$. In this case, there was a slow development of cracks and the fracture surface was covered mostly with trans-granular stress corrosion cracking (TGSCC) features. 

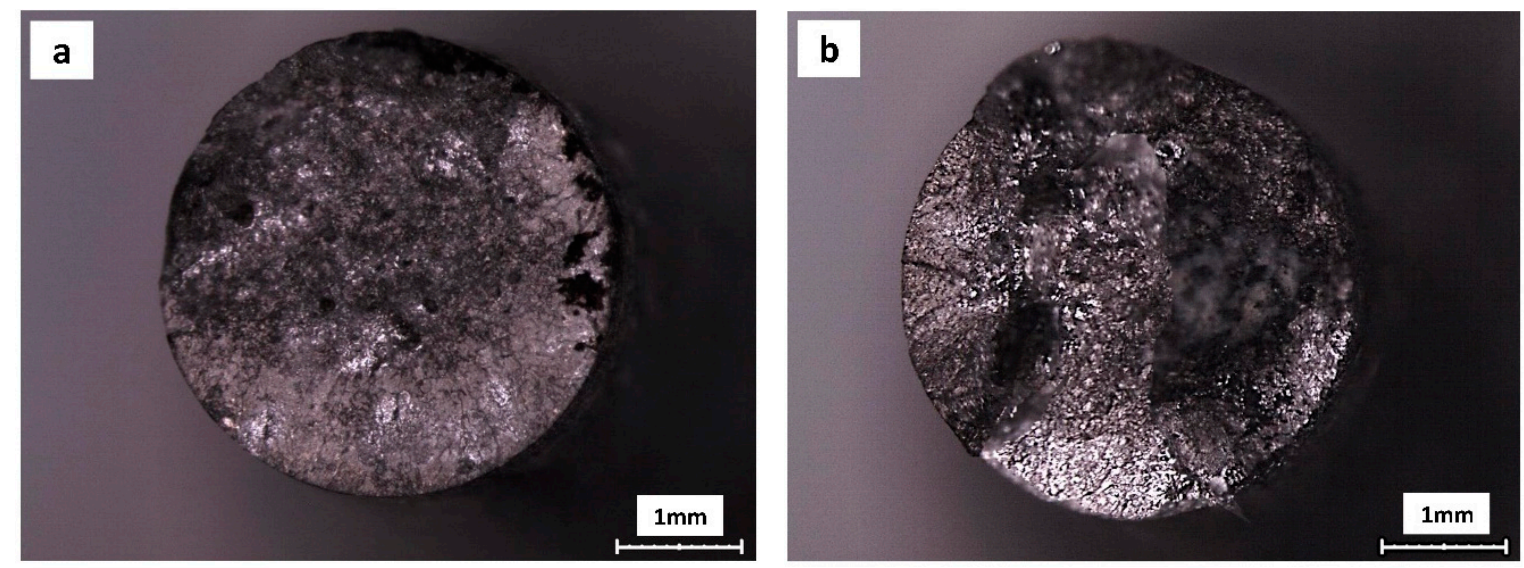

Figure 6. The typical fracture surface obtained after SSRT analysis at a strain rate of $2.5 \times 10^{-5} \mathrm{~s}^{-1}$ in PBS solution: (a) Mg-5Zn-1Nd and (b) Mg-5Zn-2Nd.
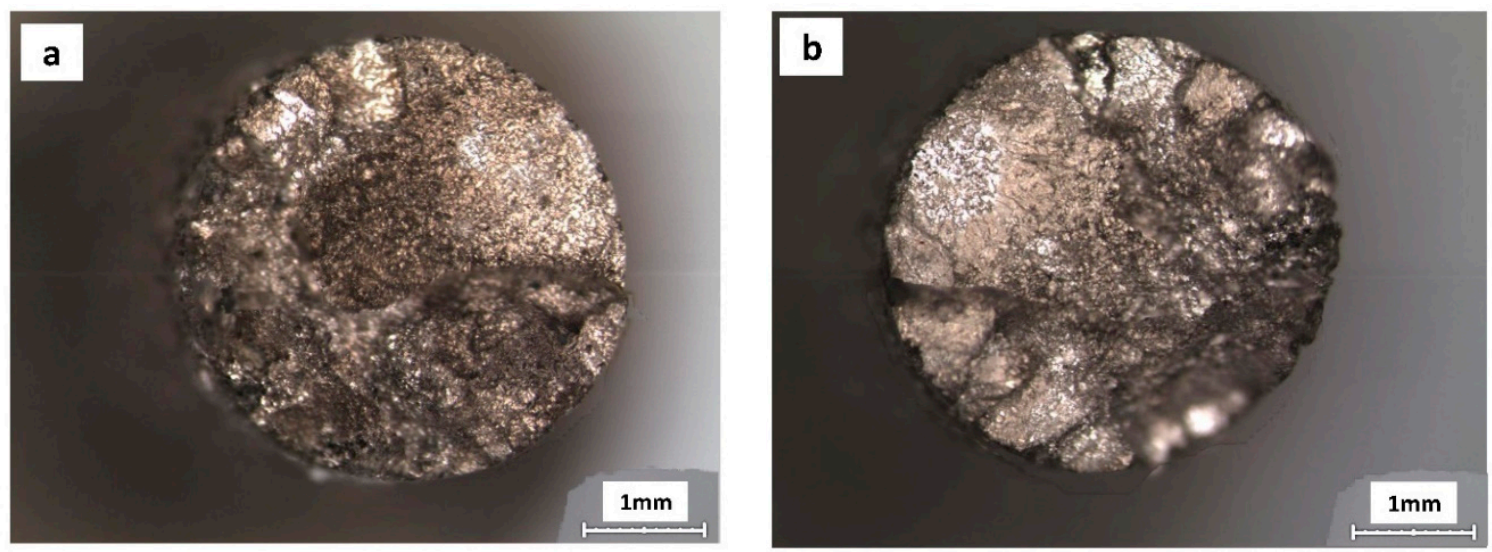

Figure 7. The typical fracture surface obtained after SSRT analysis at a strain rate of $2.5 \times 10^{-6} \mathrm{~s}^{-1}$ in PBS solution: (a) Mg-5Zn-1Nd and (b) Mg-5Zn-2Nd.

In order to evaluate the effect of the cyclic loading, the low cycle corrosion fatigue (LCCF) tests were carried out in a PBS solution and in air (as a relatively non-corrosion environment). The life spans of all the tested alloys in the PBS and in air in terms of the cycles to failure are shown in Figure 8. As expected, all the tested alloys exhibited a reduced fatigue life span in the PBS solution compared with in air due to the corrosiveness of the PBS environment. In addition, the fatigue life span of the alloys containing the $\mathrm{Nd}$ was very slightly increased compared to that of the base alloy $\mathrm{Mg}-5 \% \mathrm{Zn}$. The corresponding fracture analysis obtained in air and in the PBS solution after the removal of the corrosion products is shown in Figures 9 and 10, respectively. This revealed that the failure of the tested alloys in the air atmosphere was purely mechanical with nearly no signs of corrosion attack during the fatigue crack initiation and propagation. However, the fractures obtained in the PBS solution showed clear signs of pitting corrosion at the circumference surface that could have played a significant role in the crack nucleation. Additionally, the fracture surfaces of the alloys containing the $\mathrm{Nd}$ showed signs of fatigue striations and a relatively increased amount of corrosion products compared to the base alloy $\mathrm{Mg}-5 \% \mathrm{Zn}$. The fatigue striations were probably formed at locations of slip bands and twin boundaries that can act as preferable sites for crack initiation [34]. The presence of the increased corrosion products at the fracture surfaces can be attributed to the relatively increased LCCF life span that enabled extra time for a corrosion attack to take place during the crack propagation. 


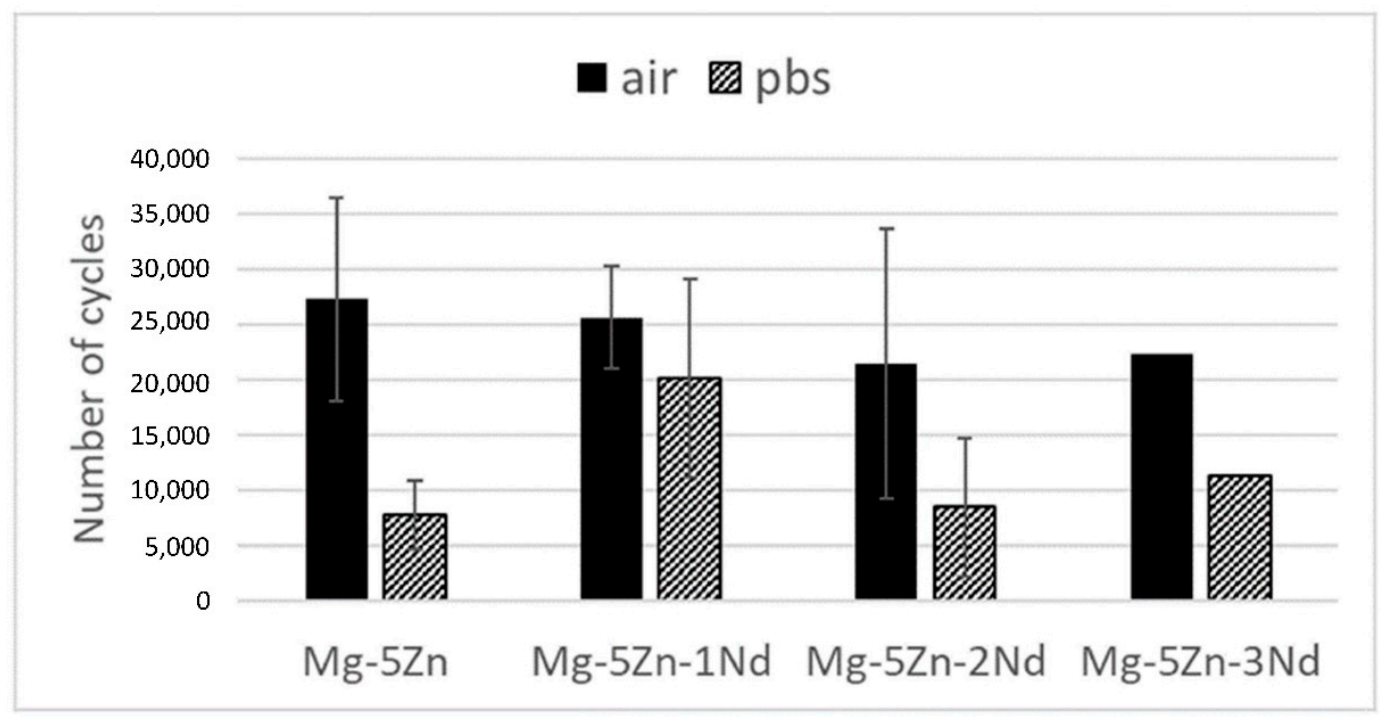

Figure 8. The life span of the tested alloys under low cycle fatigue conditions as obtained in air and the PBS solution.
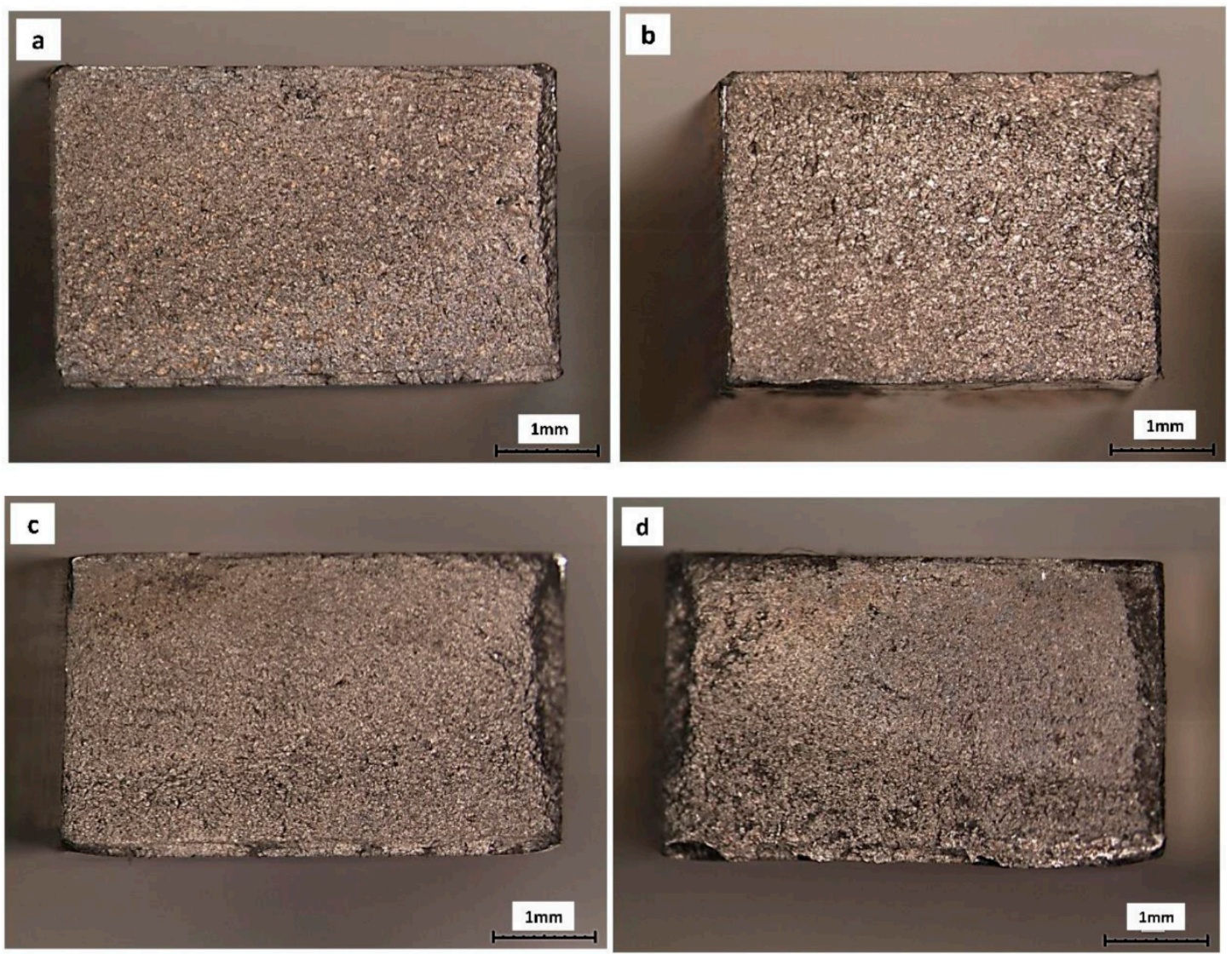

Figure 9. The typical fracture surfaces obtained after low cycle fatigue in air: (a) Mg-5Zn, (b) Mg-5Zn- $1 \mathrm{Nd}$, (c) Mg-5Zn-2Nd and (d) Mg-5Zn-3Nd. 

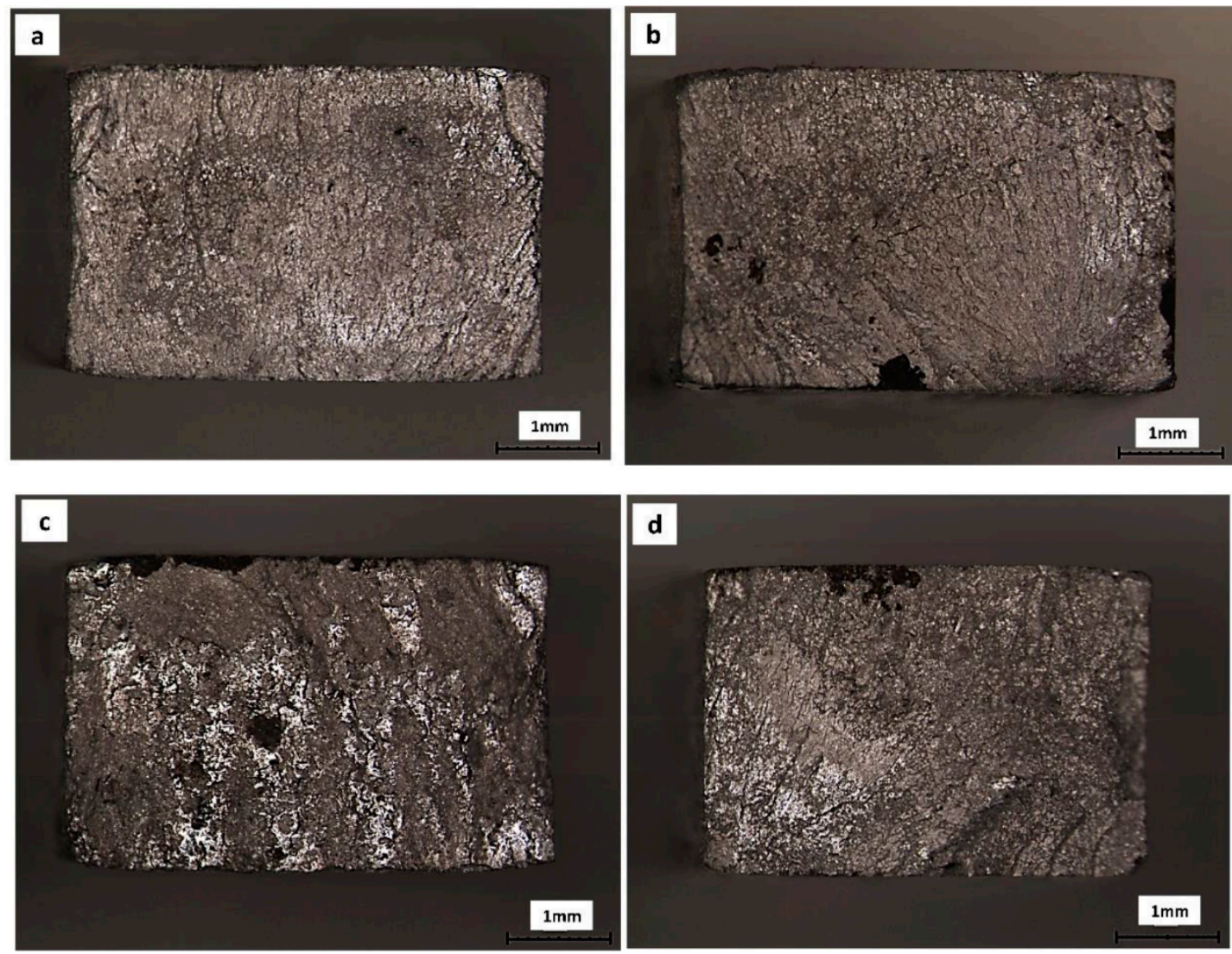

Figure 10. The typical fracture surfaces obtained after the LCCF in the PBS solution: (a) Mg-5Zn, (b) Mg-5Zn-1Nd, (c) Mg-5Zn-2Nd and (d) Mg-5Zn-3Nd.

\section{Discussion}

Our previous study [27] clearly demonstrated two important findings: (i) the general corrosion resistance of a $\mathrm{Mg}-5 \mathrm{Zn}$ alloy with up to $3 \mathrm{wt} \% \mathrm{Nd}$ was quite similar in terms of immersion test, potentiodynamic polarization and electrochemical impedance analysis; and (ii) the addition of up to $3 \mathrm{wt} \% \mathrm{Nd}$ improved the specific strength of Mg-5Zn alloy mainly due to the formation of W-phase at grain boundaries. The importance of increasing the specific strength of the base alloy (Mg-5Zn) by the addition of $\mathrm{Nd}$ means that the actual weight of the biodegradable implant can be reduced. Consequently, the detrimental hydrogen gas release, which can increase the danger of gas embolism, can be reduced accordingly. The results obtained by the present study clearly illustrate that the stress corrosion susceptibility in terms of the SSRT and LCCF examinations was not affected by the addition of up to $3 \%$ $\mathrm{Nd}$ to the base alloy, beyond the inherent differences in the mechanical properties of the alloys. In the case of the SSRT analysis, the differences between the tested alloys in terms of their UTS and elongation vs. strain rate (Figures 3 and 4) clearly indicate that they comply with the inherent mechanical properties of the alloys as obtained by our previous study [27]. From fractography examinations of the tested alloys after SSRT failure, it was evident that while a high strain rate regime of $2.5 \times 10^{-5} \mathrm{~s}^{-1}$ and $2.5 \times 10^{-6} \mathrm{~s}^{-1}$ (Figures 6 and 7 ,respectively) created conditions for typical overload failure, a reduced strain rate of $2.5 \times 10^{-7} \mathrm{~s}^{-1}$ created conditions for stress corrosion cracking. Overall, the fractography analysis revealed that the stress corrosion sensitivity of all the tested alloys was similarly increased as the strain rate was reduced. This was due to the increased exposure time of the corrosive medium as indicated by the time to failure versus strain rate. This basically means that the surface passivation of the base alloy and the alloys with $\mathrm{Nd}$ additions was stable to a similar extent. In fact, the secondary phases at grain boundaries generated by the $\mathrm{Nd}$ additions did not have any significant effect on the surface film stability and re-passivation capability. In addition, a micro-galvanic corrosion attack 
that may have taken place between the secondary phases and the matrix was insignificant in all the tested alloys. This complies with comparative studies [35,36], which indicate that plastic deformation such as extrusion, as carried out by the present study, may reduce the micro-galvanic effect of the secondary phases due to their homogenized distribution. For example, Chen et al. [36] showed that the SCC resistance of a ZK40 alloy with additions of Sr was different in as-cast and in-forged conditions. According to their study, the plastic deformation can suppress the adverse effect of Sr on the SCC susceptibility due to grain refining and a uniform distribution of the secondary phase, in contrast to the microstructure in an as-cast alloy. The microstructure modifications by heat treatment may also influence the failure modes of $\mathrm{Mg}-\mathrm{Zn}$ alloys $[37,38]$.

Generally, two main mechanisms are responsible for crack initiation and propagation under stress corrosion conditions: (i) anodic dissolution at a film-free crack tip that causes crack extension and further crack propagation, characterized by inter-granular stress corrosion cracking (IGSCC); and (ii) atomic hydrogen generated during the cathodic reaction of $\mathrm{Mg}$ alloys that can penetrate the $\mathrm{Mg}$ matrix and induce cracking, characterized by trans-granular stress corrosion cracking (TGSCC) $[39,40]$. For example, Mg-Zn-RE alloys [41,42] are susceptible to SCC via a mechanism that combines the effect of the anodic dissolution and hydrogen assisted cracking. Therefore, the nature and stability of the surface film that develops on $\mathrm{Mg}$ alloys is critical for their SCC performance. In our present study, in the SSRT analysis carried out at a high strain rate $\left(2.5 \times 10^{-5} \mathrm{~s}^{-1}\right)$, with relatively short time to failure, the mode of failure was purely mechanical. However, at a slow strain rate $\left(2.5 \times 10^{-7} \mathrm{~s}^{-1}\right)$, with a relatively long time to failure, a significant amount of hydrogen could be generated and consequently penetrate the alloy matrix and induce embrittlement. Under these conditions, surface cracks are formed and the SCC propagation is determined by the balance between the re-passivation and embrittlement at the crack tip $[23,43]$.

Under cyclic loading and in corrosive media, the above basic stress corrosion mechanisms could be applicable as suggested by Jafari et al. [44]. The increased life span in air compared to the PBS, as presented in Figure 8, indicates a similar susceptibility of $\mathrm{Mg}-5 \mathrm{Zn}$ with up to $3 \mathrm{Nd}$ alloys to corrosion fatigue. Relating to the fatigue tests in air as presented in Figure 9, the fracture surface can be divided into three clear regions - the crack initiation, crack propagation, and final rupture-as observed by other studies on $\mathrm{Mg}$ alloys $[45,46]$. The crack nucleation in this case probably took place at the micro-pores that are present on the surface. This assumption complies with the observation of Gu et al. [34] that claims that fatigue cracks in $\mathrm{Mg}$ alloys in an air atmosphere start from inherent surface defects. Relating to the corrosion fatigue tests in the PBS solution and as presented by the fractography analysis in Figure 10, the relatively reduced life span can be attributed to a pitting corrosion attack that acts as the incubation stage for crack nucleation. The fact that pitting corrosion can have a dominant detrimental effect on the corrosion fatigue life span of the Mg based alloys was already clearly presented by Bian et al. [47].

\section{Conclusions}

The addition of up to $3 \% \mathrm{Nd}$ to a $\mathrm{Mg}-5 \% \mathrm{Zn}$ alloy did not have any significant effect on the stress corrosion susceptibility in terms of the SSRT analysis and LCCF examination, beyond the inherent variations in the mechanical properties of the tested alloys. This was explained in terms of the surface film stability that was nearly unaffected by the additions of the $\mathrm{Nd}$, and by the fact that the secondary phases at the grain boundaries in the form of the $\mathrm{W}$-phase $\left(\mathrm{Mg}_{3}(\mathrm{Nd}, \mathrm{Y})_{2} \mathrm{Zn}_{3}\right)$ and T-phase $\left(\mathrm{Mg}_{4}(\mathrm{Nd}, \mathrm{Y}) \mathrm{Zn}_{2}\right)$ did not generate any significant detrimental micro-galvanic effect. Comparatively, the formation of the $\mathrm{W}$-phase at the grain boundaries of a $\mathrm{Mg}-5 \mathrm{Zn}-2 \mathrm{Nd}$ alloy introduces the optimal specific strength, and hence this alloy can be considered as a preferable structural material for biodegradable implants. 
Author Contributions: Supervision, O.H.; writing-original draft, L.E.; writing-review and editing, E.A. All authors have read and agreed to the published version of the manuscript.

Funding: This research received no external funding.

Conflicts of Interest: The authors declare no conflict of interest.

\section{References}

1. Witte, F. The history of biodegradable magnesium implants: A review. Acta Biomater. 2010, 6, 1680-1692. [CrossRef]

2. Witte, F.; Kaese, V.; Haferkamp, H.; Switzer, E.; Meyer-Lindenberg, A.; Wirth, C.J.; Windhagen, H. In vivo corrosion of four magnesium alloys and the associated bone response. Biomaterials 2005, 26, 3557-3563. [CrossRef] [PubMed]

3. Waizy, H.; Seitz, J.M.; Reifenrath, J.; Weizbauer, A.; Bach, F.W.; Meyer-Lindenberg, A.; Denkena, B.; Windhagen, H. Biodegradable magnesium implants for orthopedic applications. J. Mater. Sci. 2013, 48, 39-50. [CrossRef]

4. Kirkland, N.T.; Birbilis, N.; Staiger, M.P. Assessing the corrosion of biodegradable magnesium implants: A critical review of current methodologies and their limitations. Acta Biomater. 2012, 8, 925-936. [CrossRef]

5. Aghion, E.; Levy, G. The effect of Ca on the in vitro corrosion performance of biodegradable $\mathrm{Mg}-\mathrm{Nd}-\mathrm{Y}-\mathrm{Zr}$ alloy. J. Mater. Sci. 2010, 45, 3096-3101. [CrossRef]

6. Song, G. Control of biodegradation of biocompatible magnesium alloy. Corros. Sci. 2007, 49, 1696-1701. [CrossRef]

7. Witte, F.; Hort, N.; Vogt, C.; Cohen, S.; Ulrich Kainer, K.; Willumeit, R.; Feyerabend, F. Degradable biomaterials based on magnesium corrosion. Curr. Opin. Solid. State Mater. Sci. 2008, 12, 63-72. [CrossRef]

8. Zhang, L.N.; Hou, Z.T.; Ye, X.; Xu, Z.B.; Bai, X.L.; Shang, P. The effect of selected alloying element additions on properties of Mg-based alloy as bioimplants: A literature review. Mater. Sci. 2013, 7, 227-236. [CrossRef]

9. Kamrani, S.; Fleck, C. Biodgradable magnesium alloys as temporary orthopeadic implants: A review. BioMetals 2019, 32, 185-193. [CrossRef]

10. Kannan, M.B.; Dietzel, W.; Blawert, C.; Alterns, A.; Lyon, P. Stress-Corrosion Cracking of Rare-earth Containing Magnesium Alloys ZE41, QE22 and Elektron 21 (WV31A) Compared with AZ80. Mater. Sci. Eng. A 2008, 480, 529-539. [CrossRef]

11. Cao, F.; Shi, Z.; Song, G.L.; Liu, M.; Dargusch, M.S.; Atrens, A. Stress corrosion cracking of several solutions heat-treated Mg-X alloys. Corros. Sci. 2015, 96, 121-132. [CrossRef]

12. Arnon, A.; Aghion, E. Stress Corrosion Cracking of nano/sub-micron E906 magnesium alloy. Adv. Eng. Mater. 2008, 8, 742-745. [CrossRef]

13. Katarivas-Levy, G.; Leon, A.; Kafri, A.; Ventura, Y.; Drelich, J.W.; Goldman, J.; Vago, R.; Aghion, E. Evaluation of biodegradable $\mathrm{Zn}-1 \% \mathrm{Mg}$ and $\mathrm{Zn}-1 \% \mathrm{Mg}-0.5 \% \mathrm{Ca}$ alloys for biomedical applications. J. Mater. Sci. Mater. Med. 2017, 28, 174. [CrossRef] [PubMed]

14. Elkaiam, L.; Hakimi, O.; Yosafovich-Doitch, G.; Ovadia, S.; Aghion, E. In Vivo Evaluation of Mg-5\%Zn-2\%Nd Alloy as an Innovative Biodegradable Implant Material. Ann. Biomed. Eng. 2020, 48, 380-392. [CrossRef] [PubMed]

15. Shi, Z.; Hofstetter, J.; Cao, F.; Uggowitzer, P.J.; Dargusch, M.S.; Atrens, A. Corrosion and Stress Corrosion Cracking of Ultra-high-purity Mg5Zn. Corros. Sci. 2015, 93, 330-335. [CrossRef]

16. Kafri, A.; Ovadia, S.; Goldman, J.; Drelich, J.; Aghion, E. The suitability of Zn-1.3\%Fe alloy as a biodegradable implant material. Metals 2018, 8, 153. [CrossRef]

17. Jafaria, S.; Raman, R.K.S.; Davies, C.H.J. Stress corrosion cracking of an extruded magnesium alloy (ZK21) in a simulated body fluid. Eng. Fract. Mech. 2018, 201, 47-55. [CrossRef]

18. Vasilev, E.; Linderov, M.; Nugmanov, D.; Sitdikov, O.; Markushev, M.; Vinogradov, A. Fatigue Performance of Mg-Zn-Zr Alloy Processed by Hot Severe Plastic Deformation. Metals 2015, 5, 2316-2327. [CrossRef]

19. Li, H.; Peng, Q.; Li, X.; Li, K.; Han, Z.; Fang, D. Microstructures, mechanical and cytocompatibility of degradable Mg-Zn based orthopedic biomaterials. Mater. Des. 2014, 58, 43-51. [CrossRef]

20. Rokhlin, L.L. Magnesium Alloys Containing RE Metals; Taylor and Francis: London, UK, 2003.

21. Ben-Hamu, G.; Eliezer, D.; Dietzel, W.; Shin, K.S. Stress corrosion cracking of new Mg-Zn-Mn wrought alloys containing Si. Corros. Sci. 2008, 50, 1505-1517. [CrossRef] 
22. Wang, B.J.; Wang, S.D.; Xu, D.K.; Han, E.H. Recent progress in fatigue behavior of Mg alloys in air and aqueous media: A review. J. Mater. Sci. Tech. 2017, 33, 1075-1086. [CrossRef]

23. Hakimi, O.; Aghion, E.; Goldman, J. Improved Stress Corrosion Cracking of a Novel Biodegradable EW62 Magnesium Alloy by Rapid Solidification, in Simulated Electrolytes. Mater. Sci. Eng. C 2015, 51, $226-232$. [CrossRef]

24. Bronfin, B.; Aghion, E.; Von-Buch, F.; Schumann, S.; Katsir, M. Die casting Magnesium alloys for elevateol temperature applications. In Proceeding of the TMS Annual meeting Magnesium Technology, New Orleans, LA, USA, 11-15 February 2001; pp. 127-130.

25. Aghion, E.; Gueta, Y.; Moscovitch, N.; Bronfin, B. Effect of yttrium additions on the properties of grain-refined Mg-3\%Nd alloy. J. Mater. Sci. 2008, 43, 4870-4875. [CrossRef]

26. Aghion, E.; Bronfin, B.; Eliezer, D.; Von Buch, F.; Schumann, S.; Friedrich, H. The art of developing new Magnesium alloys for high temperature applications. Mater. Sci. Forum 2003, 419-422, 407-418. [CrossRef]

27. Elkaiam, L.; Hakimi, O.; Goldman, J.; Aghion, E. The Effect of Nd on Mechanical Properties and Corrosion Performance of Biodegradable Mg-5\%Zn Alloy. Metals 2018, 8, 438. [CrossRef]

28. Kaya, A.; Uzan, P.; Eliezer, D.; Aghion, E. Electron microscopical investigation of as cast AZ 91 D alloy. Mater. Sci. Tech. 2000, 16, 1001-1006. [CrossRef]

29. Unigovski, Y.B.; Lothongkum, G.; Gutman, E.M.; Alush, D.; Cohen, R. Low-cycle Fatigue Behavior of 316L-type Stainless Steel in Chloride Solutions. Corros. Sci. 2009, 51, 3014-3020. [CrossRef]

30. Feng, H.; Yang, Y.; Chang, H. Influence of W phase on mechanical properties and damping capacity of Mg-Zn-Y-Nd-Zr alloys. Mater. Sci. Eng. A 2014, 609, 7-15. [CrossRef]

31. Padezhnova, E.M.; Mel'nik, E.V.; Dobatkina, T.V. Study of phase equilibriums in magnesium-zinc-yttrium system. Russ. Metall. Eng. Trans. 1979, 1, 179.

32. Padezhnova, E.M.; Mel'nik, E.V.; Miliyevskiy, R.A.; Dobatkina, T.V.; Kinzhibalo, V.V. Magnesium-zincyttrium system. Russ. Metall. Eng. Trans. 1982, 4, 185.

33. Yang, J.; Wang, J.; Wang, L.; Wu, Y.; Wang, L.; Zhang, H. Microstructure and mechanical properties of Mg-4.5Zn-xNd (x=0, 1 and 2, wt \%) alloys. Mater. Sci. Eng. A 2008, 479, 339-344. [CrossRef]

34. Gu, X.N.; Zhou, W.R.; Zheng, Y.F.; Cheng, Y.; Wei, S.C.; Zhong, S.P.; Xi, T.F.; Chen, L.J. Corrosion Fatigue Behavior of Two Biomedical Mg Alloys-AZ91D and WE43-In Simulated Body Fluid. Acta Mater. 2010, 6, 4605-4613. [CrossRef]

35. Merson, D.; Vasilev, E.; Markushev, M.; Vinogradov, A. On the corrosion of ZK60 magnesium alloy after severe plastic deformation. Lett. Mater. 2017, 7, 421-427. [CrossRef]

36. Chen, L.; Sheng, Y.; Wang, X.; Zhao, X.; Liu, H.; Li, W. Effect of Microstructure and Distribution of the Second Phase on the Stress Corrosion Cracking of Biodegradable Mg-Zn-Zr-xSr Alloys. Materials 2018, 11, 551. [CrossRef] [PubMed]

37. Wang, B.J.; Xu, D.K.; Sun, J.; Han, E.H. Effect of grain structure on the stress corrosion cracking (SCC) behavior of an as-extruded Mg-Zn-Zr alloy. Corr. Sci. 2019, 157, 347-356. [CrossRef]

38. Prabhu, D.B.; Nampoothiri, I.; Elakkiya, V.; Narmadha, R.; Selvakumar, R.; Sivasubramanian, R.; Gopalakrishnan, P.; Ravi, K.R. Elucidating the role microstructural modification on stress corrosion cracking of biodegradable Mg-4Zn alloy in simulated body fluid. Mater. Sci. Eng. C 2020, 106. [CrossRef]

39. Winzer, N.; Atrens, A.; Song, G.; Ghali, E.; Dietzel, W.; Kainer, K.U.; Hort, N.; Blawert, C. A Critical Review of the Stress Corrosion Cracking (SCC) of Magnesium Alloys. Adv. Eng. Mater. 2005, 7, 659-693.

40. Winzer, N.; Atrensa, A.; Dietzel, W.; Raja, V.S.; Song, G.; Kainer, K.U. Characterization of stress corrosion cracking (SCC) of Mg-Al alloys. Mater. Sci. Eng. A 2008, 488, 339-351.

41. Zhou, L.F.; Liu, Z.Y.; Wu, W.; Li, X.G.; Du, C.W.; Jian, B. Stress corrosion cracking behavior of ZK60 magnesium alloy under different conditions. Inter. J. Hydrog. Energy 2017, 42, 26162-26174. [CrossRef]

42. Choudhary, L.; Raman, R.K.S.; Hofstetter, J.; Uggowitzer, P.J. In-vitro Characterization of Stress Corrosion Cracking of Aluminium-free Magnesium Alloys for Temporary Bio-implant Application. Mater. Sci. Eng. C 2014, 42, 629-636. [CrossRef]

43. Prabhu, D.B.; Dhamotharan, S.; Sathishkumar, G.; Gopalakrishnan, P.; Raavi, K.R. Stress-Corrosion Cracking of Biodegaradable Mg-4Zn Alloy in Simulated Body Fluid at Different Strain Rates-A Fractography Investigation. Mater. Sci. Eng. A 2018, 730, 223-231. [CrossRef]

44. Jafari, S.; Harandi, S.H.; Reman, R.K.S. A Review of Stress-Corrosion Cracking and Corrosion Fatigue of Magnesium Alloys for Biodegradable Implant Application. JOM 2015, 67, 1143-1153. [CrossRef] 
45. Yu, D.; Zhang, D.; Sun, J.; Luo, Y.; Xu, J.; Zhang, H.; Pan, F. High Cycle Fatigue behavior of Extruded and Double-aged Mg-6Zn-1Mn Alloy. Mater. Sci. Eng. A 2016, 662, 1-8. [CrossRef]

46. Xu, D.K.; Liu, L.; Xu, Y.B.; Han, E.H. The Fatigue Behavior of I-Phase Containing As-cast Mg-Zn-Y-Zr Alloy. Acta Mater. 2008, 56, 985-994. [CrossRef]

47. Bian, D.; Zhou, W.; Liu, Y.; Li, N.; Zheng, Y.; Sun, Z. Fatigue Behaviors of HP-Mg, Mg-Ca and Mg-Zn-Ca Biodegradable Metals in air and Simulated Body Fluid. Acta Biomater. 2016, 41,351-360. [CrossRef] [PubMed] 